\title{
Influence of soil moisture and surface roughness heterogeneity on modeled climate
}

\author{
Katherine Klink $^{1}$, Cort J. Willmott ${ }^{2}$ \\ ${ }^{1}$ Department of Geography, University of Minnesota, 414 Social Sciences Building, Minneapolis, Minnesota 55455, USA \\ ${ }^{2}$ Center for Climatic Research, Department of Geography, University of Delaware, Newark, Delaware 19716, USA
}

\begin{abstract}
Numerical and observational studies have documented the climatic importance of land surface variability, especially in soil moisture and surface roughness. Land surface representations within global climate models, however, have been based on global vegetation data sets that characterize the surface as invariant at scales smaller than about $(100 \mathrm{~km})^{2}$. Within climate model grid areas, the vegetation data are spatially aggregated once more to areas on the order of $10^{5} \mathrm{~km}^{2}$ and are assigned to a single, spatially homogeneous vegetation type. In this study, we examine land surface variability within a $(100 \mathrm{~km})^{2}$ grid cell (about $1^{\circ}$ of latitude by $1^{\circ}$ of longitude) using a 3 -dimensional mesoscale atmosphere-land surface model. Our investigation focuses on changes in the coverage and geographic pattern of irrigated maize (corn) and non-irrigated bare soil. Maize and bare soil are among the most disparate land covers that occur together in the present-day landscape and they exemplify highly heterogeneous spatial mosaics. Our simulations indicate that increasing the area of bare soil downwind of irrigated maize produces a nearly linear increase in daily average surface temperatures, along with a linear decrease in the average latent heat flux. Bare soil upwind of irrigated maize, however, forces a more nonlinear response. The largest effects occur when small areas of bare soil are introduced into the domain. Simulations with several mosaics containing $50 \%$ irrigated maize and $50 \%$ bare soil also suggest that changes in the spatial arrangement of the land surface alone can result in differences in areaaveraged surface temperatures and near-surface air temperatures of up to $1^{\circ} \mathrm{C}$. Our results additionally suggest that subgrid-scale area weighting schemes should yield better surface representations than the assignment of a single homogeneous surface type. It also appears that subgrid-scale area weighting may need to account for the spatial distribution of the vegetation within a grid cell.
\end{abstract}

KEY WORDS: Surface-atmosphere interaction - Energy balance - Climate modeling

\section{INTRODUCTION}

Land surfaces are an important component of the climate system, and nearly all general circulation models (GCMs) now include land surface representations (e.g. Sellers et al. 1986, Wilson et al. 1987, Abramopoulos et al. 1988, Verseghy et al. 1993). Observational as well as model-based studies have described the effects of land surface changes on both the local and global climate (e.g. Mintz 1984, Mahfouf et al. 1987, André et al. 1990, Segal \& Arritt 1992). Soil moisture and surface roughness, in particular, have been found to be most influential in determining the surface climate and the energy balance.

One limitation for studies of surface-atmosphere interactions is the assumption of surface homogeneity within GCM grid cells, the smallest of which currently are about $1^{\circ}$ of latitude by $1^{\circ}$ of longitude (roughly $10^{4} \mathrm{~km}^{2}$ ). A number of investigators have attempted to describe the errors that may result from this simplification of the land surface (e.g. Avissar \& Pielke 1989, Koster \& Suarez 1992, Bonan et al. 1993, Ducoudré et al. 1993). Their methodology has been to partition the grid cell among several surface types, each representing a percentage of the total cell area. Atmospheric properties at the lowest model level are used to drive the energy balance of each subgrid area. The surface fluxes that result are areally weighted to provide a grid-cell-averaged surface response, which then is applied uniformly to the atmosphere within the grid cell. These studies do not, however, allow the atmosphere within the cell to respond differentially to the heterogeneous surface forcing, and do not take into account the spatial distribution of subgrid elements 
within the cell. The size of errors or biases that may result from this neglect of surface geography are unknown.

Our interest, therefore, is in assessing some of the possible consequences of using aggregated land surface representations within climate models, with specific consideration of the effects of the geographical distribution of surface types within model grid cells. Our approach is to use a 3-dimensional mesoscale atmosphere-land surface model to simulate the effects of heterogeneous surface representations at subgrid scale. Land surface mosaics are made up from irrigated maize (corn) and fallow (bare) soil. These 2 surface types are of interest because of their coexistence in many of the world's irrigated farming regions. Many agricultural areas within the United States, for example, exhibit a pattern of irrigated cropland adjacent to fallow fields (cf. Segal et al. 1989, Doran et al. 1992). Global land-use data sets sometimes also include a designator of 'irrigated' cultivation. Because soil moisture is an extremely important variable in climate model simulations, classification of a grid cell as irrigated rather than non-irrigated can be significant.

\section{Soil moisture influences}

Soil moisture influences the climate of a region most directly through its affects on the latent heat flux. Evapotranspiration is enhanced when adequate soil water is available to plants. It also is true that the more radiative energy is used for latent heat flux, the less sensible heat is available within the near-surface environment. When there is a dearth of soil water, evapotranspiration is reduced, and surface and air temperatures will increase. An extreme example of the climatic impact of variable soil water availability was provided by Shukla \& Mintz (1982) who contrasted 'wet soil' and 'dry soil' global climate simulations. Their modeled July surface temperatures in the dry soil simulation were warmer than for wet soil by 15 to $25^{\circ} \mathrm{C}$. Largescale rainfall and circulation patterns also were altered significantly. Other model investigations have described the smaller-scale climatic effects of changes in soil moisture. Segal et al. (1988), for example, showed that well-watered vegetation, transpiring freely, essentially behaves as if it were a completely wet soil surface. Contrasts in their model between non-stressed vegetation and a dry, bare soil resulted in air temperature differences of $3^{\circ} \mathrm{C}$ and mesoscale circulations as strong as the sea breeze. When the vegetation was stressed due to a soil water deficit, the simulations showed that the surface behaves like a dry soil, and temperature and circulation differences between areas were minor. Similar results were observed by Mahfouf et al. (1987) when soils with different moisture characteristics were juxtaposed. Again, localized circulations nearing the intensity of the sea breeze were the result. Model simulations by Avissar (1991), Avissar \& Pielke (1991), and Mascart et al. (1991) underscore the importance of stomatal control of water loss, particularly because stomatal resistance reacts nonlinearly to changes in soil moisture.

\section{Surface roughness influences}

Surface roughness also plays an important role in the surface energy balance by changing the efficiency of energy transport near the earth's surface. Wilson et al. (1987) and Dickinson \& Henderson-Sellers (1988), for instance, showed that when the roughness length of modeled tropical forests was decreased, the sensible and latent heat fluxes from the forest were reduced, and vegetation and soil temperatures were increased. Dickinson \& Henderson-Sellers noted that the differences in roughness alone accounted for nearly half the total temperature change that occurred as a result of modeled deforestation. Analogous to the evapotranspiration study of Shukla \& Mintz (1982), Sud et al. (1988) undertook a comparison of modeled climates using a uniform land surface roughness of $45 \mathrm{~cm}$. These results were compared to simulations using a land surface roughness of $0.02 \mathrm{~cm}$ (the model's roughness length for oceans). While their model produced only small changes in the surface fluxes of sensible and latent heat, large changes occurred in atmospheric circulation and the distribution of rainfall, particularly along coastal margins where the roughness discontinuities were large. Klink (1992) also found that discontinuities were important when they occurred over smaller scales. In a study of vegetation patterning at sub-GCM grid scales, it was found that changes in surface roughness contributed to localized circulation patterns that, in some cases, enhanced the influences of the vegetation discontinuity; in other cases, the circulation served to diminish the effects of surface heterogeneity.

\section{Subgrid-scale variability}

Scale restrictions within which most GCMs operate dictate that model characterizations of land surfaces must be coarse. Subgrid-scale variability consequently has not been represented well, even though the climatic effects can be significant. Wetzel \& Chang (1988) modeled several of the effects of subgrid-scale soil moisture variability and demonstrated that grid cell averaged soil moistures could produce an underestimate of evaporation from a cell as large as $400 \mathrm{~W} \mathrm{~m}^{-2}$. 
Lhomme (1992) compared the fluxes predicted by models using linearly averaged aerodynamic and surface resistance values with those predicted using a nonlinear resistance-based function. It was found that the nonlinear weighting yielded meaningful improvements in the estimated areal fluxes of sensible and latent heat. Within a GCM grid square, HendersonSellers \& Pitman (1992) considered the effects of representing a grid cell by the dominant vegetation type. Results were compared to characterizing the cell with an areally weighted average of the parameters for each vegetation type it contained. Their findings suggested that the dominant-classification approach significantly underrepresented the climatic effects of the minority vegetation types. Progressively increasing the relative amount of one of the vegetation types produced a nonlinear response, with small areas playing a comparatively large role in determining the area-averaged climate. Studies of the effects of surface heterogeneity within climate models (cf. Avissar \& Pielke 1989, Koster \& Suarez 1992, Bonan et al. 1993, Ducoudré et al. 1993) also suggested that subgrid area weighting can provide improved representations of land surface fluxes, though these have neglected to account specifically for surface geography.

\section{LAND SURFACE REPRESENTATIONS WITHIN CLIMATE MODELS}

Vegetation and soil properties used within most climate models are taken from available global land cover data sets, which typically characterize the land surface at a $1^{\circ}$ of latitude by $1^{\circ}$ of longitude resolution (cf. Matthews 1983, Wilson \& Henderson-Sellers 1985, Willmott \& Klink 1986). Existing land surface classifications include varying numbers of categories of natural vegetation (usually on the order of 20 to 30) and some include one or more classes of agricultural land use. Aggregating vegetation information up to this $\left(1^{\circ} \times 1^{\circ}\right)$ scale means that heterogeneous areas must be represented by a single vegetation type, normally the spatially dominant one within the cell. If no vegetation type comprises a majority of the area, a subjective determination of the vegetation class typically is made.

\section{A COUPLED MESOSCALE ATMOSPHERE-LAND SURFACE MODEL}

\section{Atmospheric component of the model}

A 3-dimensional mesoscale atmospheric model developed by Pielke and colleagues (Pielke 1974, Mahrer \& Pielke 1977, 1978, McNider \& Pielke 1981) is used as the atmospheric driver for our simulations. It has undergone extensive verification and has been applied in a wide range of investigations (e.g. McCumber \& Pielke 1981, Steyn \& McKendry 1988, Segal et al. 1989). Because the model allows for variable resolution of the atmosphere and land surface, it is possible to obtain a finer resolution of near-surface processes than typically is available in larger-scale models. Klink (1992) coupled vegetation and soil parameterizations with this atmospheric model.

Six variables govern the atmospheric state: the easterly and northerly wind components, vertical velocity, potential temperature, specific humidity, and atmospheric pressure. These quantities are computed from 4 prognostic equations (the horizontal equations of motion, the thermodynamic equation, and a continuity equation for water vapor) and 2 diagnostic functions (the hydrostatic equation and the incompressible continuity equation). Prognostic equations include eddy stress terms, arising from the correlation of subgridscale properties, that are solved using horizontal and vertical eddy exchange coefficients. Vertical exchange coefficients are computed separately for stable and unstable conditions, while the horizontal coefficients are estimated as a function of wind speed and grid size. Model equations are described more fully in several papers (e.g. Pielke 1974, Mahrer \& Pielke 1977, Klink 1992).

The governing equations are evaluated on a finite difference mesh. In order to minimize the numerical effects of the model's lateral boundaries, the model domain includes a larger number of horizontal grid points than actually are needed to represent the domain of interest. Vertical grid increments are smallest near the surface and expand upward to provide enhanced resolution of near-surface exchange processes

\section{Land surface component of the model}

Our land surface model solves separate energy budgets for the soil and the overlying vegetation canopy. Vegetation is cast as a single layer and is characterized by its height, leaf area index ( $L A I)$, and leaf albedo and transmissivity. Several soil layers also are represented, with soil hydraulic properties assigned based on soil type.

The canopy energy balance is

$$
R S_{\mathrm{v}} a_{\mathrm{v}}+R L_{\mathrm{v}} \varepsilon_{\mathrm{v}}-R E_{\mathrm{v}}=H_{\mathrm{v}}+L_{\mathrm{v}}
$$

where $R S$ and $R L$ denote shortwave (solar) and longwave radiation, respectively, incident on the land surface, $a$ is the surface shortwave absorptivity $(a=1-\alpha-\tau$, where $\alpha$ is the surface albedo and $\tau$ the transmissivity), 
$\varepsilon$ is the surface longwave emissivity, $R E$ is emitted (outgoing) surface longwave radiation $\left(R E=\varepsilon \sigma T^{4}\right.$, where $\sigma$ is the Stefan-Boltzmann constant and $T$ is the surface temperature), $H$ is the sensible heat flux, and $L$ is the latent heat flux. The subscript $v$ denotes vegetation. The canopy is assumed to have negligible heat capacity, so a conducted heat flux is not included in Eq. (1).

Radiative flux terms are computed following Avissar \& Mahrer (1988) and take into account radiative exchanges between the vegetation and the soil. Shortwave energy received at the surface as direct and diffuse radiation is treated separately in the energy budget. Canopy albedo is computed as a function of leaf optical properties, $L A I$, and solar zenith angle (Monteith 1973, Dickinson \& Hanson 1984, Shuttleworth \& Wallace 1985). Transmission of radiation through the canopy is dependent on LAI, solar zenith, and leaf transmissivity (Monteith 1973). Soil albedo is calculated as a function of soil moisture and solar zenith angle from data provided by Idso et al. (1975).

Sensible heat flux from the canopy is computed using the 'resistance' approach (Monteith 1973) as

$$
H_{v}=\frac{\rho c_{p}\left(T_{v}-T_{a}\right)}{r_{a}}
$$

where $T_{v}$ is the canopy temperature, $T_{a}$ is the air temperature, $\rho$ is the density of air, $c_{p}$ is the specific heat of air, and $r_{\mathrm{a}}$ is the aerodynamic resistance, computed as a function of atmospheric stability (Mahrer \& Pielke 1977). Latent heat flux is estimated by the PenmanMonteith combination equation (Monteith 1973):

$$
L_{v}=\frac{\Delta\left(R_{n}-G\right)+\frac{\rho c_{p} \delta e}{r_{\mathrm{a}}}}{\Delta+\gamma\left(1+\frac{r_{c}}{r_{d}}\right)}
$$

Net radiation is denoted by $R_{n}, G$ is the conducted heat flux (assumed to be zero for the canopy), $\delta e$ is the atmospheric vapor pressure deficit, $\Delta$ is the slope of the saturation vapor pressure curve, $\gamma$ is the psychrometric constant, and $r_{\mathrm{c}}$ is the canopy resistance.

Canopy resistance depends on plant stomatal resistance (Dickinson 1984, Shuttleworth \& Wallace 1985) $\left(r_{s}\right)$ according to

$$
I_{c}=\frac{r_{5}}{n \sigma_{f} L A I}
$$

with $n=1$ for amphistomatous leaves (stomata on one side) and $n=2$ for hypostomatous leaves. The variable $\sigma_{f}$ represents the relative vegetative cover $(0=$ bare ground, 1 = closed canopy). Stomatal resistance is determined from

$$
r_{\mathrm{S}}=r_{\mathrm{s} \min } f(R S) f\left(T_{a}\right) f(W) f(\delta e)
$$

where $r_{\mathrm{s} \min }$ is the minimum leaf stomatal resistance and $W$ is the soil water content. Each function $f(\cdot)$ ranges between 1 and $1 / \gamma_{r}$, where $\gamma_{r}=\left(r_{\mathrm{s} \min } / r_{\mathrm{s} \max }\right)$ and $r_{\mathrm{s} \text { max }}$ is the cuticular resistance of the leaf.

Shortwave radiation affects stomatal response according to

$$
f(R S)=\frac{1+\frac{R S}{R S_{2}}}{\gamma_{r}+\frac{R S}{R S_{2}}}
$$

where $R S_{2}$ is the flux of shortwave radiation at which Eq. (6) is about twice its minimum value (Dickinson 1984). Stomatal response to air temperature is taken from Jarvis (1976):

$$
f\left(T_{\mathrm{a}}\right)= \begin{cases}{\left[b_{1}\left(T_{\mathrm{a}}-T_{\mathrm{L}}\right)\left(T_{\mathrm{H}}-T_{\mathrm{a}}\right)^{b_{2}}\right]^{-1},} & \left(T_{\mathrm{a}}-T_{\mathrm{L}}\right)\left(T_{\mathrm{H}}-T_{\mathrm{a}}\right)^{b_{2}} \geq \frac{1}{b_{2} \gamma_{r}} \\ \frac{1}{\gamma_{r}} & \text { otherwise }\end{cases}
$$

where $b_{1}=1 /\left[\left(T_{0}-T_{\mathrm{L}}\right)\left(T_{\mathrm{H}}-T_{0}\right)^{\mathrm{b}_{2}}\right], b_{2}=\frac{T_{\mathrm{H}}-T_{0}}{T_{\mathrm{H}}-T_{\mathrm{L}}}, T_{0}$ is the temperature at which the resistance is minimum, and $T_{\mathrm{L}}$ and $T_{H}$ are the lower and upper air temperatures, respectively, at which $r_{\mathrm{s}}=r_{\mathrm{S} \text { max }}$.

The response to changes in soil water is based on Willmott et al. (1985b) and is given by

$$
f(W)= \begin{cases}{\left[1-\exp \left(-6.68 \frac{W}{W_{\text {sat }}}\right)\right]^{-1},} & W \geq 6.11 \times 10^{-3} W_{\text {sat }} \\ \frac{1}{\gamma_{r}} & \text { otherwise }\end{cases}
$$

where $W_{\text {sat }}$ is the soil saturated water content. Atmospheric humidity effects are represented as

$$
f(\delta e)= \begin{cases}{[1-\eta(\delta e)]^{-1},} & \delta e \leq \frac{0.96}{\gamma_{r}} \\ \frac{1}{\gamma_{r}} & \text { otherwise }\end{cases}
$$

where $\eta$ is a vegetation-dependent constant (Jarvis 1976).

Parameters used to evaluate each of these response functions were compiled from a variety of sources (Table 1). Parameters were adjusted where necessary to provide reasonable estimates of vegetation latent heat flux when compared to measured values from grass- and crop-covered lysimeters (Fig. 1, Table 2).

The energy balance for soil is

$$
R S_{\mathrm{g}} a_{\mathrm{g}}+R L_{\mathrm{g}} \varepsilon_{\mathrm{g}}-R E_{\mathrm{g}}=H_{\mathrm{g}}+L_{\mathrm{g}}+G_{\mathrm{g}}
$$

where the subscript $g$ denotes a ground (soil) heat flux. As for vegetation, the radiative terms are computed following Avissar \& Mahrer (1988) and take into account direct and diffuse solar radiation components. 
Table 1 Parameters used in the calculation of stomatal resistance. Data compiled from a Dickinson (1984), börner et al. (1979), 'Nobel (1983), ${ }^{\mathrm{d}}$ Willmott \& Klink (1986), and ${ }^{\mathrm{e}}$ through model calibration

\begin{tabular}{|cccccc|}
\hline Category & $r_{\mathrm{s} \min }\left(\mathrm{s} \mathrm{m}^{-1}\right)$ & $r_{\mathrm{s} \max }\left(\mathrm{s} \mathrm{m}^{-1}\right)$ & $R S_{2}\left(\mathrm{~W} \mathrm{~m}^{-2}\right)$ & $T_{L}, T_{0}, T_{\mathrm{H}}\left({ }^{\circ} \mathrm{C}\right)$ & $\eta\left(\mathrm{mb}^{-1}\right)$ \\
\hline Maize & $160^{\mathrm{b}}$ & $4000^{\mathrm{c}}$ & $100^{\mathrm{a}}$ & $0,25,50^{\mathrm{d}}, \mathrm{e}$ & $0.020^{\text {d }}$ \\
\hline
\end{tabular}

Table 2. Model evaluation statistics for the calculation of latent heat flux $\left(\mathrm{W} \mathrm{m}^{-2}\right)$. These statistics are described in Willmatt et al. (1985a)

\begin{tabular}{|lr|}
\cline { 2 - 2 } Statistic & Value \\
\hline Observed mean & 107.026 \\
Predicted mean & 107.358 \\
Observed standard deviation & 65.257 \\
Predicted standard deviation & 66.101 \\
Mean absolute error & 8.861 \\
Root mean square error (RMSE) & 11.613 \\
RMSE (systematic) & 0.384 \\
RMSE (unsystematic) & 11.606 \\
Index of agreement & 0.992 \\
Modified index of agreement & 0.912 \\
Regression intercept & 0.649 \\
Regression slope & 0.997 \\
\hline
\end{tabular}

Soil sensible heat flux is computed using the resistance approach and the latent heat flux is determined from the Penman-Monteith equation. A soil resistance formulation $\left(r_{\text {so }}\right)$, used in place of the canopy resistance in Eq. (3), is given by

$$
r_{\mathrm{so}}=r_{\mathrm{so} \min } f(W)
$$

where $r_{50 \text { min }}$ is the minimum soil resistance, estimated to be $250 \mathrm{~s} \mathrm{~m}^{-1}$ (Shuttleworth \& Wallace 1985). Heat conducted into the soil is computed from

$$
G_{\mathrm{g}}=-\kappa\left(\frac{T_{\mathrm{g}}-T_{\mathrm{g}-1}}{z_{\mathrm{g}}-z_{\mathrm{g}-1}}\right)
$$

where $\kappa$ is the thermal conductivity, $T_{\mathrm{g}}$ is the soil temperature at depth $z_{\mathrm{g}}=0$ (the soil surface), and $T_{\mathrm{g}-1}$ is the soil temperature at depth $z_{g-1}$ (Monteith 1973, Hillel 1982).

\section{INITIALIZATION OF MODELED ATMOSPHERE, CANOPY AND SOIL}

Conditions are intended to be representative of a typical clear-sky, midsummer day in the east-central United States (Table 3). Initial fields are assigned based on average July conditions at Dayton $\left(40^{\circ} \mathrm{N}, 84^{\circ} \mathrm{W}\right)$ and Coshocton, Ohio $\left(40^{\circ} \mathrm{N}, 82^{\circ} \mathrm{W}\right)$. Average surface air temperature and pressure as well as vertical profiles of temperature and humidity are taken from Crowe (1971) for 1962 to 1966 at Dayton. Cubic splines were used to interpolate the data given by Crowe to the heights represented in the model (Table 4). Average July soil temperature profiles are provided by Chang (1958) for 1942 to 1955 at Coshocton. Soil temperatures were interpo-

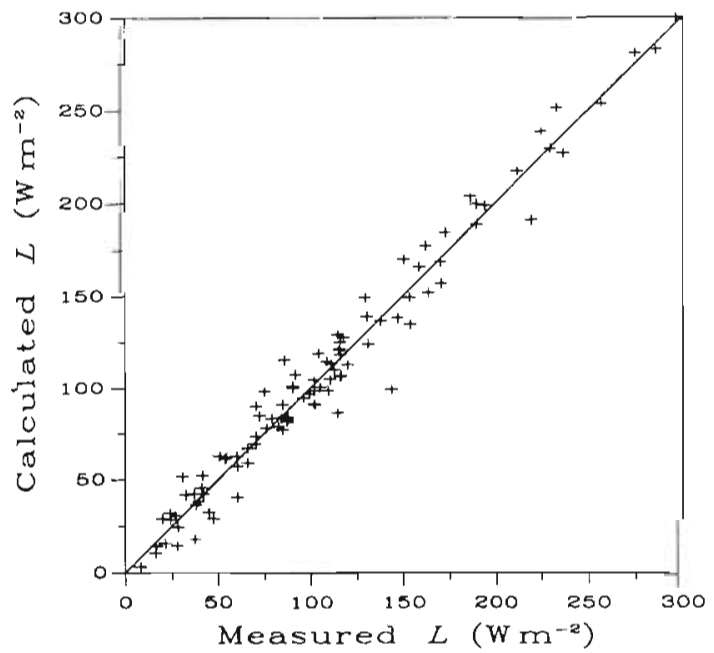

Fig. 1. Scatterplot of the observed and predicted (using Eq. 3 and the parameters in Table 1) latent heat flux ( $L$ ) from 11 grass- and crop-covered lysimeters

\begin{tabular}{|c|c|}
\hline Latitude & $40^{\circ} \mathrm{N}$ \\
\hline Day of the year & July 15 \\
\hline Initial surface temperature & $23^{\circ} \mathrm{C}$ (Crowe 1971) \\
\hline Initial surface pressure & $980 \mathrm{mb}$ (Crowe 1971) \\
\hline Large-scale wind velocity & $\begin{array}{l}\text { Westerly }\left(260^{\circ}\right) \text { at } 3 \mathrm{~m} \mathrm{~s}^{-1} \\
\text { (Peixoto \& Oort } 1992 \text { ) }\end{array}$ \\
\hline Soil roughness length & $0.5 \mathrm{~cm}$ (Oke 1978) \\
\hline $\begin{array}{l}\text { Vegetation type } \\
\text { from Willmott \& Klink (1986): }\end{array}$ & Maize \\
\hline Height & $2 \mathrm{~m}$ \\
\hline Leaf area index & 3 \\
\hline Leaf albedo & 0.23 \\
\hline Leaf transmissivity & 0.10 \\
\hline $\begin{array}{l}\text { Soil type } \\
\text { from Clapp \& Hornberger (1978): }\end{array}$ & Loam \\
\hline Saturation water content & $0.451 \mathrm{~cm}^{3} \mathrm{~cm}^{-3}$ \\
\hline Saturation hydraulic conductivity & $6.95 \times 10^{-4} \mathrm{~cm} \mathrm{~s}^{-1}$ \\
\hline Time step & $12 \mathrm{~s}$ \\
\hline Horizontal grid interval & $5 \mathrm{~km}$ \\
\hline
\end{tabular}

Table 3. Parameters used in the model simulations 
Table 4 . Initial temperature and humidity profiles used in the simulations. Heights are in meters above ground level

\begin{tabular}{|ccc|}
\hline Height $(\mathrm{m})$ & Temperature $\left({ }^{\circ} \mathrm{C}\right)$ & $\begin{array}{c}\text { Specific } \\
\text { humidity }\left(\mathrm{g} \mathrm{kg}^{-1}\right)\end{array}$ \\
\hline 10 & 22.9 & 11.9 \\
24 & 22.9 & 11.8 \\
44 & 22.8 & 11.8 \\
71 & 22.6 & 11.7 \\
109 & 22.4 & 11.6 \\
163 & 22.2 & 11.4 \\
239 & 21.8 & 11.2 \\
344 & 21.2 & 10.9 \\
492 & 20.4 & 10.4 \\
698 & 19.4 & 9.8 \\
987 & 17.8 & 9.0 \\
1392 & 15.6 & 7.8 \\
1959 & 12.5 & 6.2 \\
2753 & 8.0 & 4.2 \\
3864 & 1.8 & 2.3 \\
5420 & -6.9 & 1.2 \\
7598 & -20.5 & 0.4 \\
10647 & -37.7 & 0.1 \\
\hline
\end{tabular}

Table 5. Initial soil profile used in the simulations

\begin{tabular}{|ccc|}
\hline Depth $(\mathrm{cm})$ & Temperature $\left({ }^{\circ} \mathrm{C}\right)$ & Root fraction \\
\hline 0 & 24.6 & 0.00 \\
5 & 23.0 & 0.00 \\
10 & 22.6 & 0.08 \\
45 & 20.8 & 0.52 \\
80 & 19.0 & 0.21 \\
120 & 16.8 & 0.14 \\
180 & 13.4 & 0.05 \\
\hline
\end{tabular}

lated using cubic splines to a depth of $45 \mathrm{~cm}$. Because Chang's data extend only to about $60 \mathrm{~cm}$, linear interpolation was used to estimate soil temperatures below this depth (Table 5). Rooting information for maize was estimated from data in Taylor \& Klepper (1973). Soil moisture in irrigated areas is assumed to be at $95 \%$ of saturation and non-irrigated soil at $50 \%$ of saturation, based on data from agricultural regions in Minnesota (D. Baker \& D. Ruschy pers. comm.). Atmospheric forcing is homogeneous across the domain at the beginning of the model run, but is modified by differential surface forcing as the simulation progresses.
Our spatial domain is $100 \mathrm{~km} \times 100 \mathrm{~km}$ with a horizontal grid spacing of $5 \mathrm{~km}$. Model lateral boundaries are located approximately $75 \mathrm{~km}$ from the analysis domain; test simulations indicated that this distance was sufficient to assure that their position had a negligible effect on the climate within the domain (Pielke 1984). Three types of surface patterns are evaluated. The first series of simulations compares a homogeneous, irrigated maize domain to increasing areas of bare soil. Domains with bare soil upwind and downwind of irrigated maize also are considered. A second series of simulations includes a 'checkerboard' mosaic (Fig. 2).

Modeled spatial domains are referred to by the coverage and geographic distribution of surface types: for example, 100M:0B denotes a domain completely covered by irrigated maize; $70 \mathrm{M}: 30 \mathrm{~B}$ refers to a domain that is $70 \%$ irrigated maize upwind of an area (comprising $30 \%$ of the domain) of bare soil (Fig. 2a); 70B:30M refers to bare soil upwind of maize (Fig. 2b); and 50Bc:50Mc signifies that the domain contains 50\% coverage each of bare soil and maize, arranged in the checkerboard pattern (Fig. 2c). In all cases, maize areas are irrigated (soil at $95 \%$ of saturation), and bare soil areas are non-irrigated (soil at $50 \%$ of saturation). Although soil moisture and surface roughness are not the only 2 variables that differ between the maize and bare soil regions, they effect the largest changes in the surface energy budget, as noted in previous modeling studies (e.g. Mahfouf et al. 1987, Dickinson \& Henderson-Sellers 1988, Segal et al. 1988, Klink 1992) and in sensitivity tests of the current model. Our analysis focuses on daytime (07:00 to 17:00 h LST) temperatures and fluxes, as this is when radiative forcing is largest and the surface response should be strongest.

\section{INFLUENCES OF LAND SURFACE HETEROGENEITY}

\section{Bare areas downwind of irrigated maize}

Surface temperatures spatially averaged over the domain $\left(\bar{T}_{\mathrm{s}}\right)$ incrementally respond to changes in the land surface mosaic. When compared to the domainaveraged surface temperature computed for $100 \%$ a)

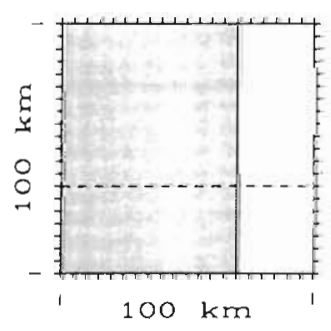

b)

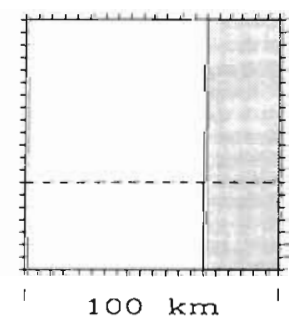

c)

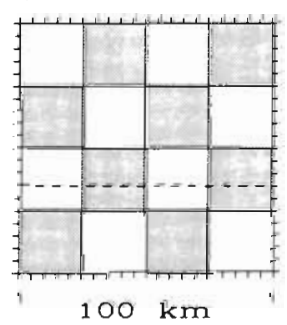

Fig. 2. Examples of surface geography and model grid (located by the tick marks along the outer edges) used in the simulations. Model lateral boundaries (not shown) are located approximately $75 \mathrm{~km}$ distant from the analysis domain, and modeled winds blow from left to right across the domain. The dashed line denotes the location of vertical crosssections. (a) Irrigated maize upwind of bare soil (70M:30B). (b) Bare soil upwind of irrigated maize (70B:30M). (c) Irrigated maize and bare soil interspersed in the checkerboard pattern (50Bc:50Mc) 


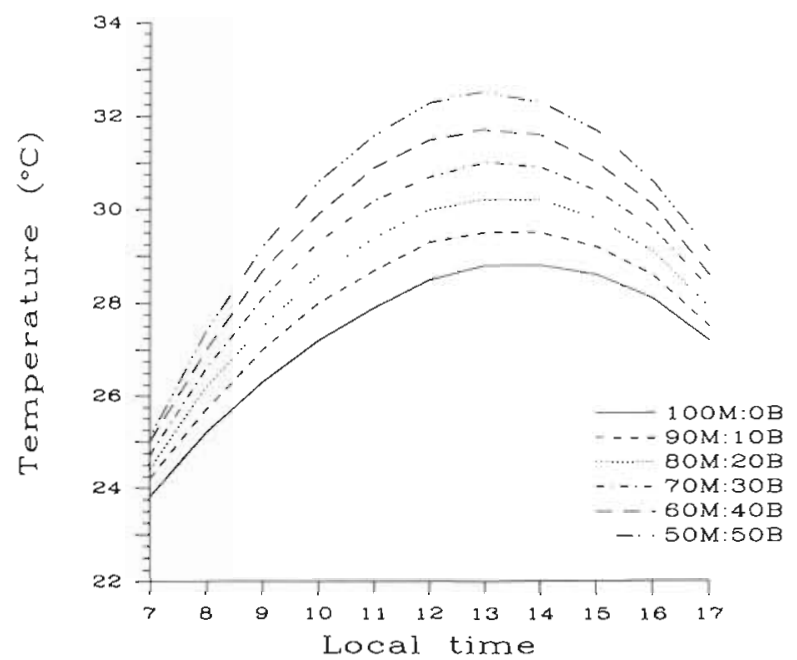

Fig. 3. Hourly area-averaged surface temperatures for homogeneous irrigated maize (100M:0B) and for surfaces with irrigated maize upwind of bare soil. For clarity of presentation only domains with $50 \%$ or more areal coverage of irrigated maize are included

coverage of irrigated maize, daily average temperatures increase by roughly the same amount for each $10 \%$ increase in the area of bare soil (Fig. 3). There is a slightly larger effect when the domain changes from $100 \mathrm{M}: 0 \mathrm{~B}$ to $90 \mathrm{M}: 10 \mathrm{~B}$, and from $10 \mathrm{M}: 90 \mathrm{~B}$ to homogeneous bare soil (0M:100B). It appears that small areas of dissimilar surface have a slightly larger impact on average surface temperature than their size alone would suggest.

Area-weighted temperature changes also are examined. They are obtained from

$$
\Delta_{\mathrm{w}} \bar{T}_{\mathrm{s}}=\frac{\bar{T}_{\mathrm{s}} \text { (model) }-\bar{T}_{\mathrm{s}}(\text { maize })}{\text { bare area }(\text { model })}
$$

where (model) refers to a model domain that contains some bare soil and (maize) refers to the homogeneous maize domain. This ratio represents the average temperature increase of the heterogeneous domain simulation over the temperature derived from the homogeneous maize control run. It is weighted (divided) by the area of bare soil in the heterogeneous domain; units are $\left({ }^{\circ} \mathrm{C} /\right.$ tenths of bare soil). The average increase in temperature of the $80 \mathrm{M}: 20 \mathrm{~B}$ surface from the maize surface, for example, is $1.17^{\circ} / 2$ or $0.58^{\circ} \mathrm{C}$ for each $10 \%$ increase in bare soil area. Temperature changes that are collinear with changes in the area of bare soil would yield an area-weighed value of $0.62^{\circ} \mathrm{C}$. For the domains examined, area-weighted temperature increases ranged from 0.58 to $0.62^{\circ} \mathrm{C}$, suggesting a strong linear response. Comparison of the modeled temperature changes - to those that would be expected if we assume a linear increase of surface temperature with increasing area of bare soil - shows

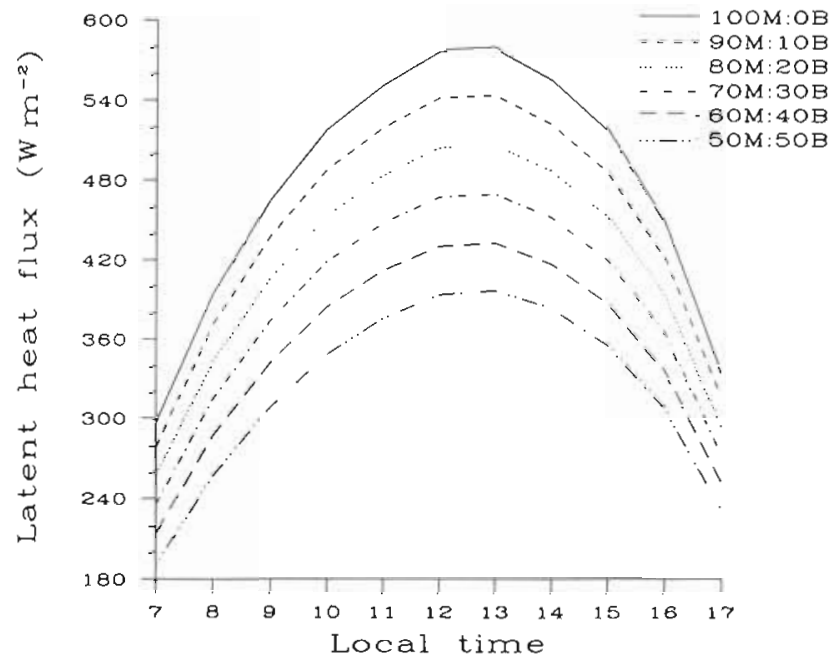

Fig. 4. Hourly area-averaged latent heat flux for homogeneous irrigated maize $(100 \mathrm{M}: 0 \mathrm{~B})$ and for surfaces with irrigated maize upwind of bare soil. For clarity of presentation only domains with $50 \%$ or more areal coverage of irrigated maize are included

that the modeled increases are very slightly smaller (by 0.1 to $0.2^{\circ} \mathrm{C}$ ) than expected. This is due to the advection of relatively cool air toward the warmer bare soil, which results in cooler than expected bare soil temperatures.

Daytime averaged (over the model domain) latent heat flux $(\bar{L})$ shows a nearly constant decrease as the area of bare soil is increased (Fig. 4). A slightly smaller change occurs when small bare areas are introduced $(10 \%$ and $20 \%)$ than for larger areas of bare soil. Areaweighted differences $\left(\Delta_{w} \vec{L}\right)$ increase very slightly as the amount of irrigated maize is reduced, although the differences are extremely small (less than $1 \mathrm{~W} \mathrm{~m}^{-2}$ ). More specifically, the decrease of latent heat flux as the area of irrigated maize is decreased (and the area of bare soil is increased) is virtually collinear with the areal proportions of bare soil and irrigated maize Latent heat flux does not seem to be as influenced as average surface temperature by small patches of bare soil or irrigated maize. It is likely that this occurs because most of the evapotranspiration takes place in the vegetated area, and the characteristics of air advected over this region are largely unaffected by the bare soil areas.

\section{Irrigated maize downwind of bare soil}

In contrast to the previous set of simulations, bare areas upwind of irrigation (Fig. 2b) have a nontrivial impact on the average surface temperature over the domain (Fig. 5, Table 6). Effects are the largest with the change from no bare soil to 10B:90M. Small-area 


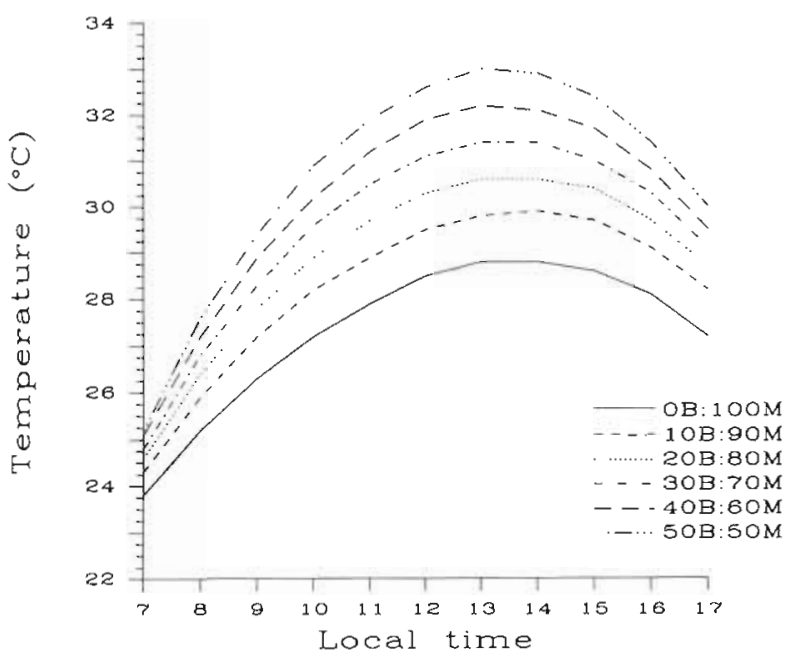

Fig. 5. Hourly area-averaged surface temperatures for homogeneous irrigated maize (0B:100M) and for surfaces with bare soil upwind of irrigated maize. For clarity of presentation only domains with $50 \%$ or more areal coverage of irrigated maize are included

effects (from bare soil areas) then decrease steadily as the size of the bare areas increase.

Changes in latent heat flux from each domain also reflect the larger impact of small areas of bare soil (Fig. 6, Table 7): the smallest decreases in latent heat flux occur when small areas of bare soil are introduced into the domain. This effect decreases steadily as the

Table 6. Summary of modeled surface temperature changes $\left({ }^{\circ} \mathrm{C}\right)$ for irrigated maize downwind of bare soil. Daytime area-averaged surface temperatures are presented as the difference $\left(\delta \bar{T}_{\mathrm{s}}\right)$ between the modeled heterogeneous domain and the homogeneous irrigated maize domain. Linearly-scaled temperature differences are included for comparison and are computed assuming that the average surface temperature increases $10 \%$ with each $10 \%$ increase in bare soil area. Area-weighted changes in temperature $\left(\Delta_{\mathrm{w}} \bar{T}_{\mathrm{s}}\right)$ are computed according to Eq. (13). The areaweighted difference represents the average change in surface temperature as the area of bare soil increases from zero

\begin{tabular}{|cccc|}
\hline $\begin{array}{c}\text { Land surface } \\
\text { geography }\end{array}$ & $\begin{array}{c}\delta \bar{T}_{\mathrm{s}} \\
\text { (linear scale) }\end{array}$ & $\begin{array}{c}\delta \bar{T}_{\mathrm{s}} \\
\text { (modeled) }\end{array}$ & $\Delta_{\mathrm{w}} \overline{\mathrm{T}}_{\mathrm{s}}$ \\
\hline 0B:100M & 0.00 & 0.00 & - \\
10B:90M & 0.62 & 0.94 & 0.94 \\
20B $80 \mathrm{M}$ & 1.24 & 1.57 & 0.78 \\
30B:70M & 1.85 & 2.17 & 0.72 \\
40B:60M & 2.47 & 2.76 & 0.69 \\
50B:50M & 3.09 & 3.35 & 0.67 \\
60B:40M & 3.71 & 3.95 & 0.66 \\
70B:30M & 4.33 & 4.54 & 0.65 \\
80B:20M & 4.94 & 5.10 & 0.64 \\
90B:10M & 5.56 & 5.64 & 0.63 \\
100B:0M & 6.18 & 6.18 & 0.62 \\
\hline
\end{tabular}

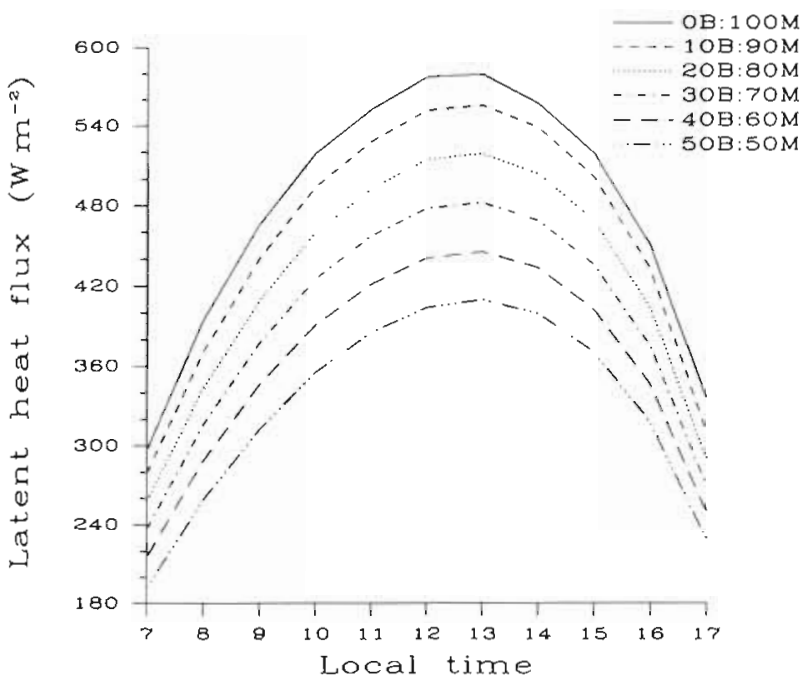

Fig. 6. Hourly area-averaged latent heat flux for homogeneous irrigated maize (OB:100M) and for surfaces with bare soil upwind of irrigated maize. For clarity of presentation only domains with $50 \%$ or more areal coverage of irrigated maize are included

area of bare soil grows larger, mirroring the trend that occurs in surface temperature. The surface response is due in large measure to the differences in soil moisture across the domain. With configurations having bare soil upwind of irrigated maize, warmer and drier air advected toward the maize increases its near-surface humidity gradient. The vegetation is not water-limited

Table 7 Summary of modeled latent heat flux changes $\left(\mathrm{W} \mathrm{m} \mathrm{m}^{-2}\right.$ ) for irrigated maize downwind of bare soil. Daytime area-averaged latent heat flux is presented as the difference $(\delta \vec{L})$ between the modeled heterogeneous domain and the homogeneous irrigated maize domain. Linearly-scaled latent heat flux differences are included for comparison and are computed assuming that the average latent heat flux decreases $10 \%$ with each $10 \%$ increase in bare soil area. Area-weighted changes in latent heat flux $\left(\Delta_{\mathrm{w}} \bar{L}\right)$ are computed in the same manner as for temperature, according to Eq. (13). The area-weighted difference represents the average change in the flux of latent heat as the area of bare soil increases from zero

\begin{tabular}{|cccc|}
\hline $\begin{array}{c}\text { Land surface } \\
\text { geography }\end{array}$ & $\begin{array}{c}\delta \bar{L} \\
\text { (linear scale) }\end{array}$ & $\begin{array}{c}\delta \bar{L} \\
\text { (modeled) }\end{array}$ & $\Delta_{\mathrm{w}} \bar{L}$ \\
\hline 0B:100M & 0.0 & 0.0 & - \\
10B:90M & -30.8 & -22.2 & -22.2 \\
10B:80M & -61.6 & -53.0 & -26.5 \\
30B:70M & -92.4 & -84.1 & -28.0 \\
40B:60M & -123.2 & -115.2 & -28.8 \\
50B:50M & -154.0 & -146.6 & -29.3 \\
60B:40M & -184.8 & -177.8 & -29.6 \\
70B:30M & -215.6 & -209.6 & -29.9 \\
80B:20M & -246.4 & -241.6 & -30.2 \\
90B:10M & -277.2 & -274.4 & -30.5 \\
100B:0M & -308.0 & -308.0 & -30.8 \\
\hline
\end{tabular}


so the larger humidity gradient drives an increase in evapotranspiration and thus a smaller-than-expected decrease in the latent heat flux. If the maize was not irrigated but rather was subjected to water-limiting conditions, advective enhancement of the latent heat flux would be much smaller, or perhaps nonexistent (cf. Mahfouf et al. 1987, Segal et al. 1988). In addition, the large roughness of maize (as compared to bare soil) enhances the transfer of sensible as well as latent heat and contributes to the nonlinear temperature change. Warm air advection also increases the temperature in this region. As a result, average surface temperatures increase more than would be expected based on the relative areal coverage of the bare soil and irrigated maize. As the size of the maize area decreases, domain-averaged advective enhancement becomes less important, and the effects on both surface temperature and latent heat flux are diminished.

Daytime domain-averaged surface temperatures generally are warmer than temperatures computed from an average based on the area of each surface type. The effect is pronounced for small areas of bare soil where the difference between modeled and linearly-averaged temperatures is about $0.3^{\circ} \mathrm{C}$ (second and third columns of Table 6). Average latent heat flux from each domain also is larger than the flux calculated based on linear weighting. Once again, differences between the modeled and linearly-averaged domain values decrease as the area of irrigated maize is reduced (second and third columns of Table 7).

\section{Spatial patterns of irrigated maize and bare soil}

Global land-surface data sets often use $50 \%$ coverage as the boundary between one surface type and another. With this in mind, we compare homogeneous irrigated maize (100M:0B) and homogeneous bare soil domains (0M:100B) with several spatial configurations, all containing a $50 \%$ areal representation of maize and of bare soil.

Surface temperature differences between a $100 \%$ irrigated maize and a $100 \%$ bare soil domain are substantial; they reach nearly $8^{\circ} \mathrm{C}$ by midday (Fig. 7). Differences in near-surface $(10 \mathrm{~m})$ air temperatures also are apparent over the 2 surfaces (Fig. 8). Domains with $50 \%$ coverage of maize and $50 \%$ coverage of bare soil generally have midday domain-averaged surface temperatures that are roughly half of the difference between completely crop-covered and completely bare domains. Changes in the spatial patterns of the land cover, however, affect these differences. Irrigated maize upwind from bare soil (50M:50B) bears greater resemblance the homogeneous crop area (100M:0B) than to the completely bare surface (OM:100B), as indi- cated by the smaller surface temperature differences (Fig. 7). Similarly, the reverse pattern (bare soil upwind from irrigated maize, 50B:50M) is more like the completely bare surface than like the completely vegetated one. A checkerboard pattern (50Bc:50Mc), which has bare soil and irrigated maize areas interspersed with

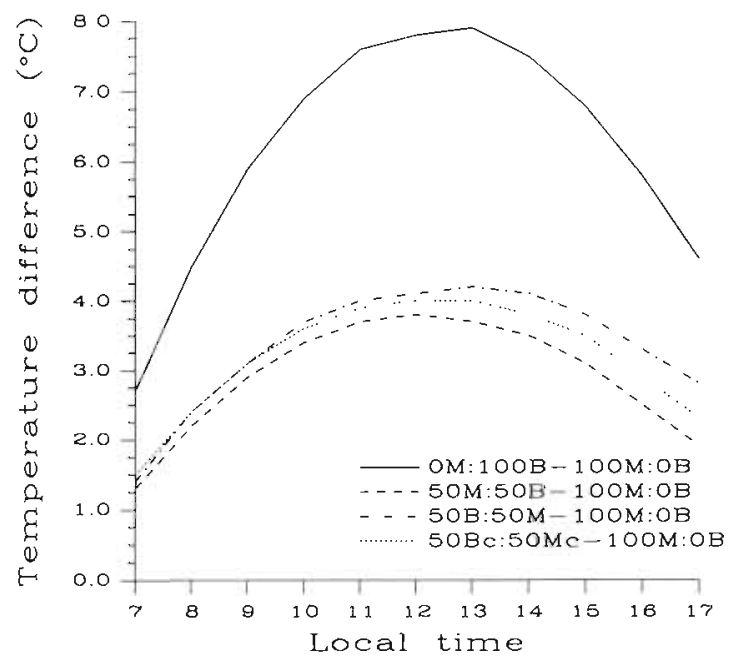

Fig. 7. Hourly area-averaged surface temperature differences between the homogeneous irrigated maize domain (100M:0B) and domains with $50 \%$ coverage of maize and bare soil. The 50M:50B domain has maize upwind of bare soil; 50B:50M has bare soil upwind of maize; and 50Bc:50Mc contains maize and bare soil arranged in the checkerboard pattern. Also included are the hourly differences between homogeneous irrigated maize and homogeneous bare soil (OM:100B)

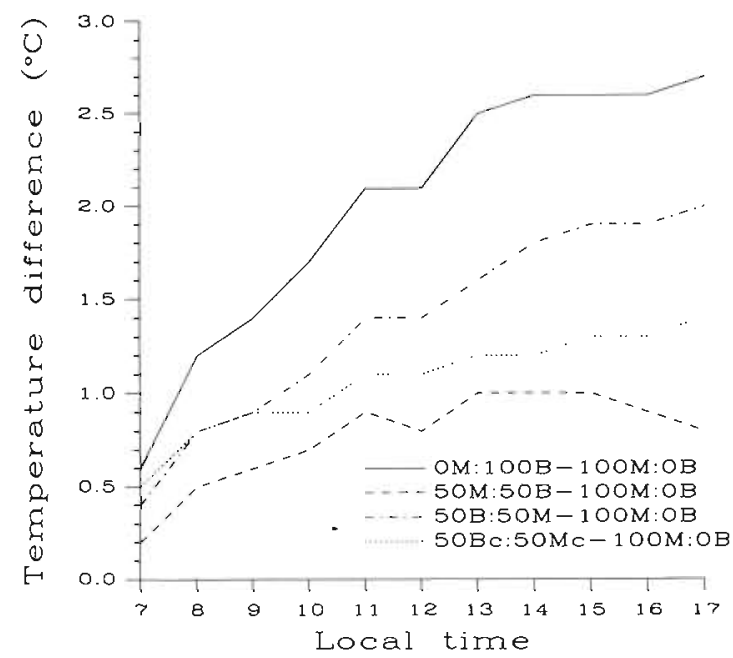

Fig. 8. Hourly area-averaged near-surface $(10 \mathrm{~m})$ air temperature differences between the homogeneous irrigated maize domain and domains with $50 \%$ coverage of maize and bare soil. Also included are the hourly differences between homogeneous irrigated maize and homogeneous bare soil. Notation is as described in Fig. 7 


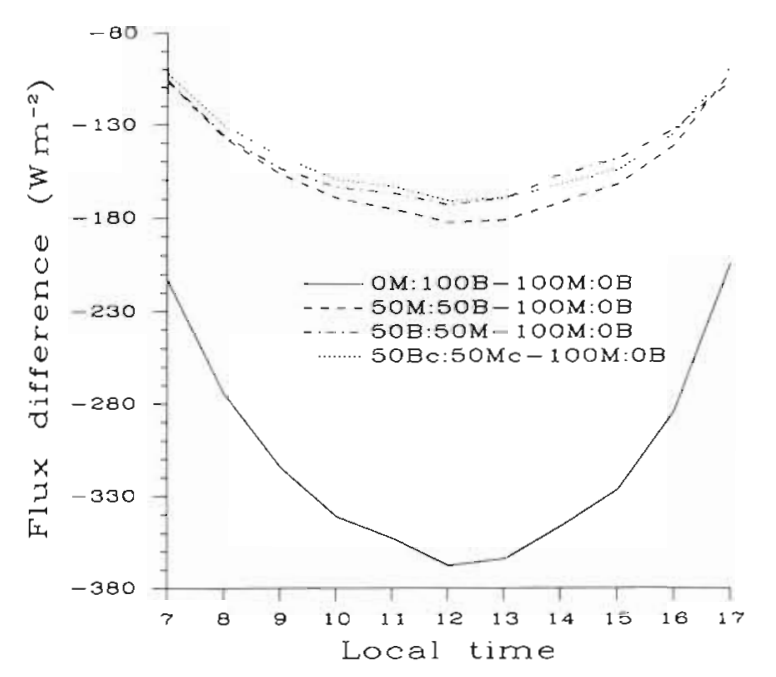

Fig. 9. Hourly area-averaged Iatent heat flux differences between the homogeneous irrigated maize domain and domains with $50 \%$ coverage of maize and bare soil. Also included are the hourly differences between homogeneous irrigated maize and homogeneous bare soil. Notation is as described in Fig. 7

one another (Fig. 2c), yields intermediate surface temperatures. Simulations using a 'reversed' checkerboard pattern (bare soil replaces maize and vice versa) produced the same domain-averaged results as the checkerboard domain. Surface temperature differences due to changes in the distribution of vegetation and soil reach almost $1^{\circ} \mathrm{C}$ by late afternoon (compare the temperatures for 50M:50B, 50B:50M, and 50Bc:50Mc in Fig. 7).

Some effects of changing spatial patterns also can be seen in the area-averaged latent heat flux differences among domains. Once again, domains with $50 \%$ irrigated maize and $50 \%$ bare soil exhibit latent heat fluxes that are approximately midway between completely bare and completely vegetated regions (Fig. 9). Spatial configuration again plays a role, with the 50M:50B surface in this instance having the largest differences from the homogeneous maize area and the smallest differences from completely bare soil. By contrast, as dry air is advected over irrigated areas in the bare/maize (50B:50M) and checkerboard domains, it enhances evapotranspiration and makes these regions appear more like the homogeneous maize.

With respect to domain-averaged evapotranspiration, early in the day the checkerboard surface (50Bc:50Mc) differs less from the homogeneous domain than does the bare/maize (50B:50M) domain (Fig. 9). In the afternoon, this pattern is reversed with evapotranspiration from the bare/maize domain slightly exceeding that from the checkerboard domain. Small-scale circulation patterns appear to be the cause of this reversal. Over the checkerboard surface, differ- ences in the surface energy balance and in the surface roughness promote the development of localized circulation cells centered approximately over the boundaries between vegetation and bare soil. Rising motion is enhanced by convergence as wind traveling over bare soil reaches crop areas and is slowed by the larger roughness. Sinking motion is enhanced by divergence as the air accelerates as it travels from the crop to the bare area (Fig. 10). These cells effectively mix the drier

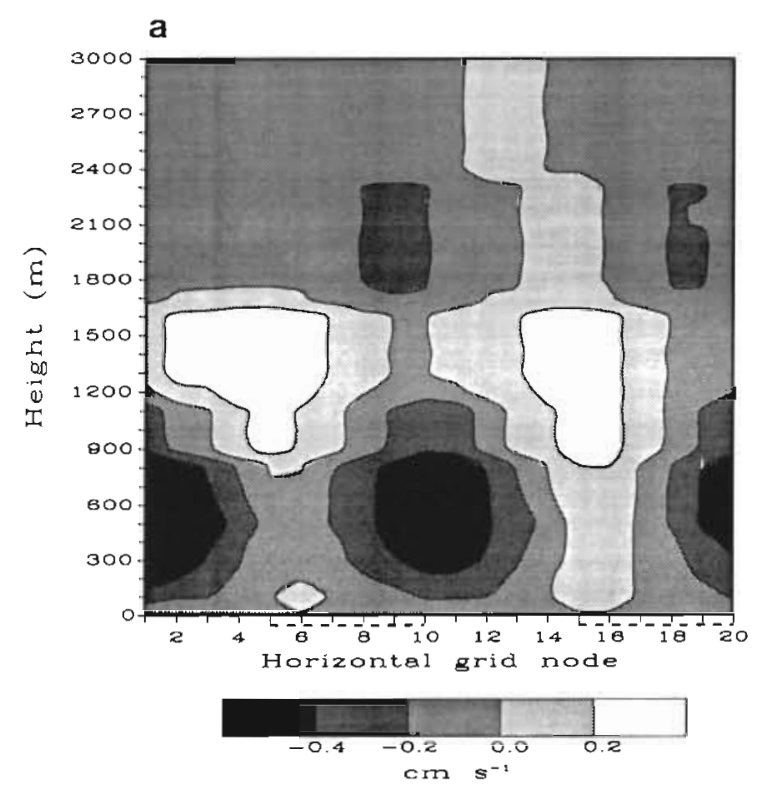

b

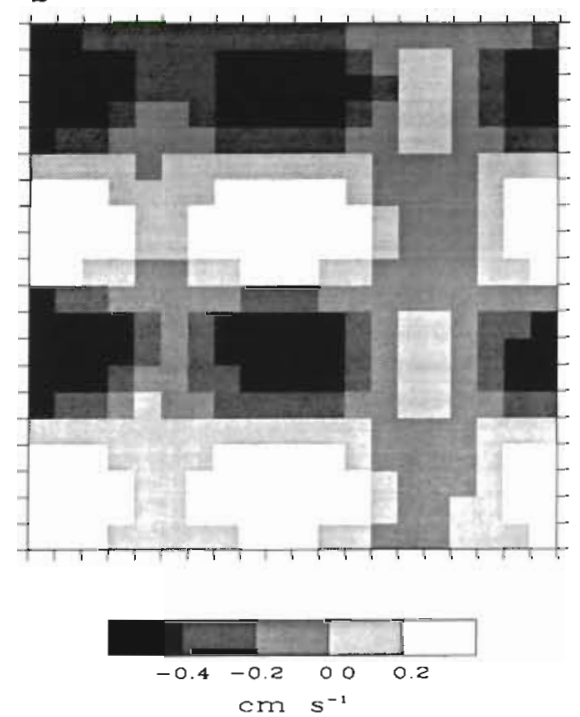

Fig. 10. (a) Vertical cross-section of the vertical velocity field in the lower atmosphere at 15:00 h for the 50Bc:50Mc surface. The cross-section is taken at the location depicted in Fig. 2. Areas of irrigated maize are indicated by a dashed line along the honzontal axis and unmarked regions are bare soil. (b) Horizontal cross-section of the vertical velocity field at $492 \mathrm{~m}$ above ground level (model level 9) at 15:00 $\mathrm{h}$ for the $50 \mathrm{Bc}: 50 \mathrm{Mc}$ surface 
and the moister air, and help to maintain a lower humidity near the maize surface. Over the bare/maize area only a single circulation cell appears, arising in part from surface convergence at the vegetation discontinuity (Fig. 11). Maize near the boundary transpires at a very high rate, moistening the air that then moves downwind over the rest of vegetated area. Because this moist, near-surface air is not mixed with drier air, the humidity over the transpiring maize is
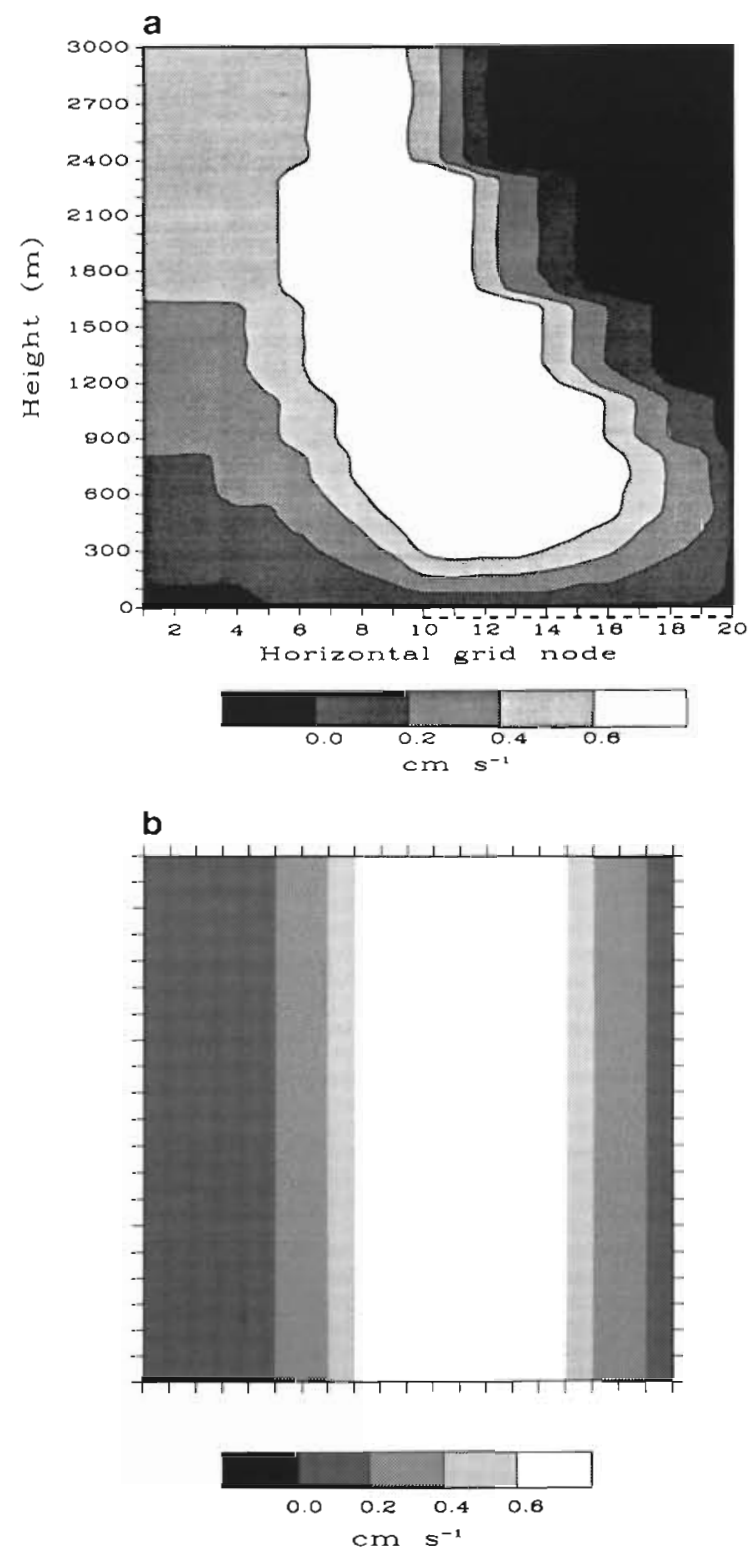

Fig. 11. (a) Vertical cross-section of the vertical velocity field in the lower atmosphere at 15:00 h for the 50B:50M surface. The cross-section is taken at the location depicted in Fig. 2. Areas of irrigated maize are indicated by a dashed line along the horizontal axis and unmarked regions are bare soil. (b) Horizontal cross-section of the vertical velocity field at $492 \mathrm{~m}$ above ground level (model level 9) at 15:00 $\mathrm{h}$ for the 50B:50M surface higher than for maize interspersed with bare soil (the checkerboard pattern). As a consequence, evapotranspiration for the bare/maize area is lower, and the difference from homogeneous maize is larger, than for the checkerboard region. The discontinuity between crops and bare soil in the 50M:50B domain also gives rise to a localized circulation, with sinking motion occurring near the discontinuity (Fig. 12). However, this pattern does not enhance evapotranspiration from
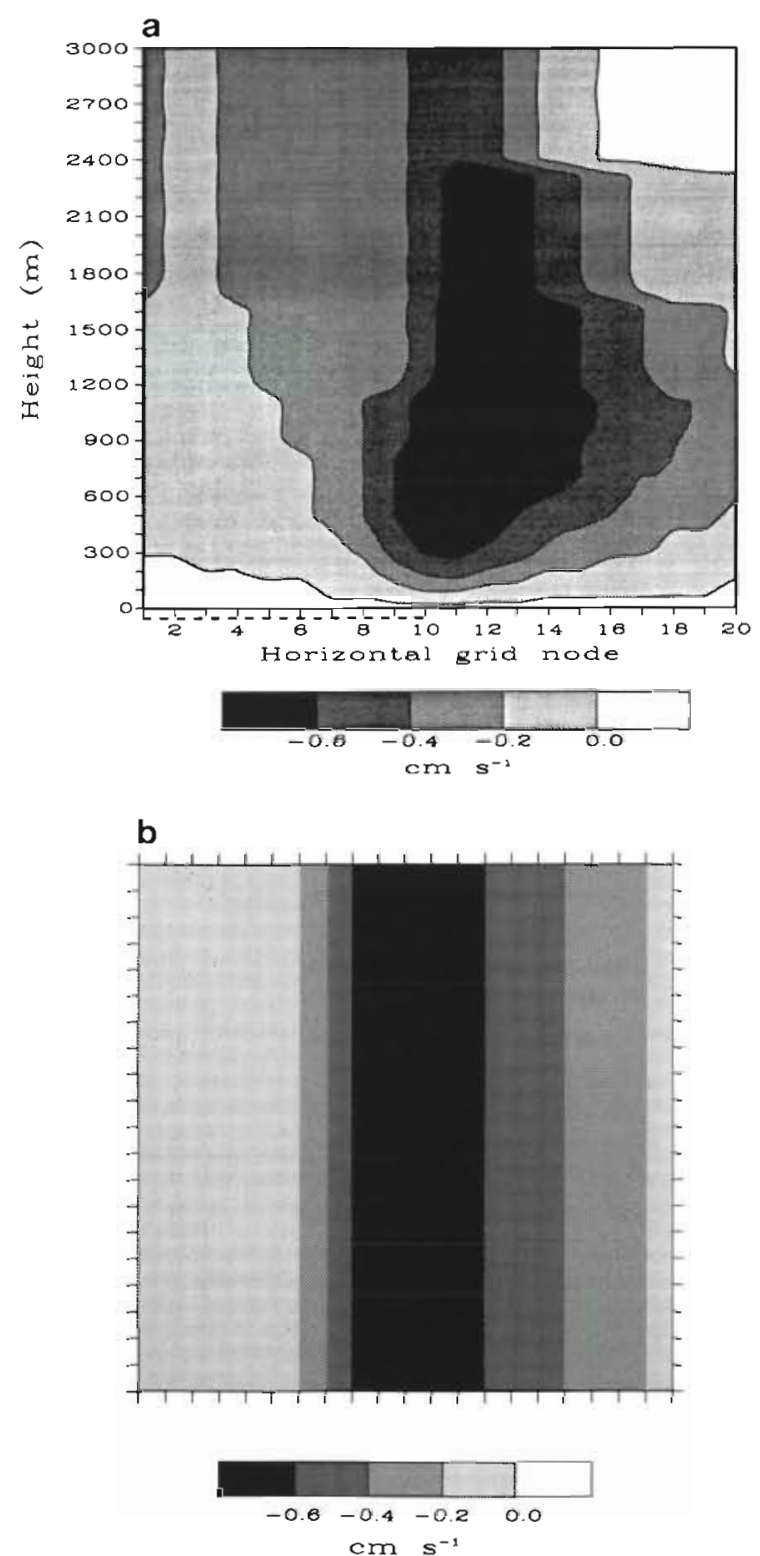

Fig. 12. (a) Vertical cross-section of the vertical velocity field in the lower atmosphere at 15:00 h for the 50M:50B surface. The cross-section is taken at the location depicted in Fig. 2. Areas of irrigated maize are indicated by a dashed line along the horizontal axis and unmarked regions are bare soil. (b) Horizontal cross-section of the vertical velocity field at $492 \mathrm{~m}$ above ground level (model level 9) at 15:00 h for the 50M:50B surface 


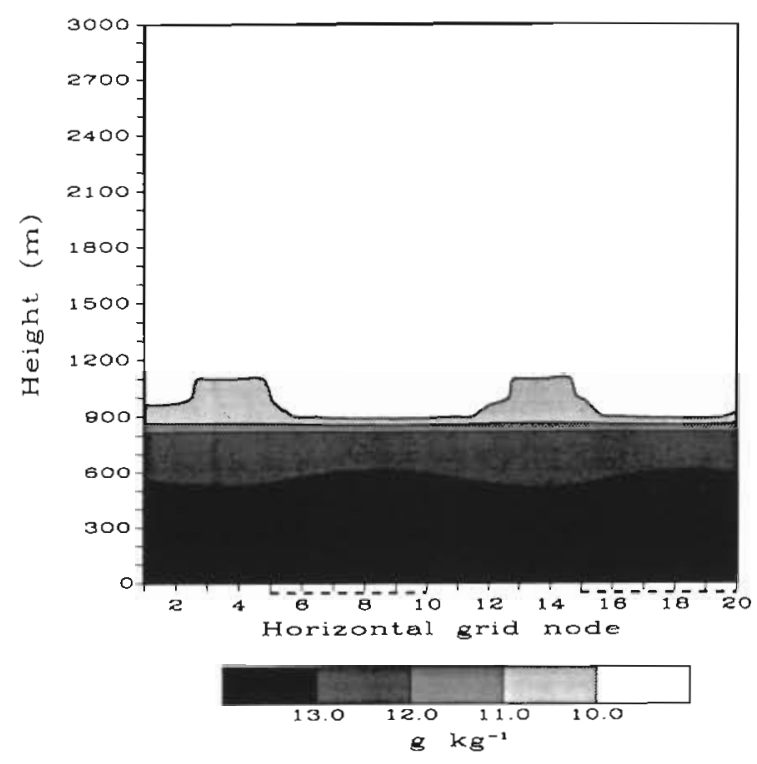

Fig. 13. Vertical cross-section of the specific humidity field in the lower atmosphere at $15: 00 \mathrm{~h}$ for the $50 \mathrm{Bc}: 50 \mathrm{Mc}$ surface. The cross-section is taken at the location depicted in Fig. 2. Areas of irrigated maize are indicated by a dashed line along the horizontal axis and unmarked regions are bare soil

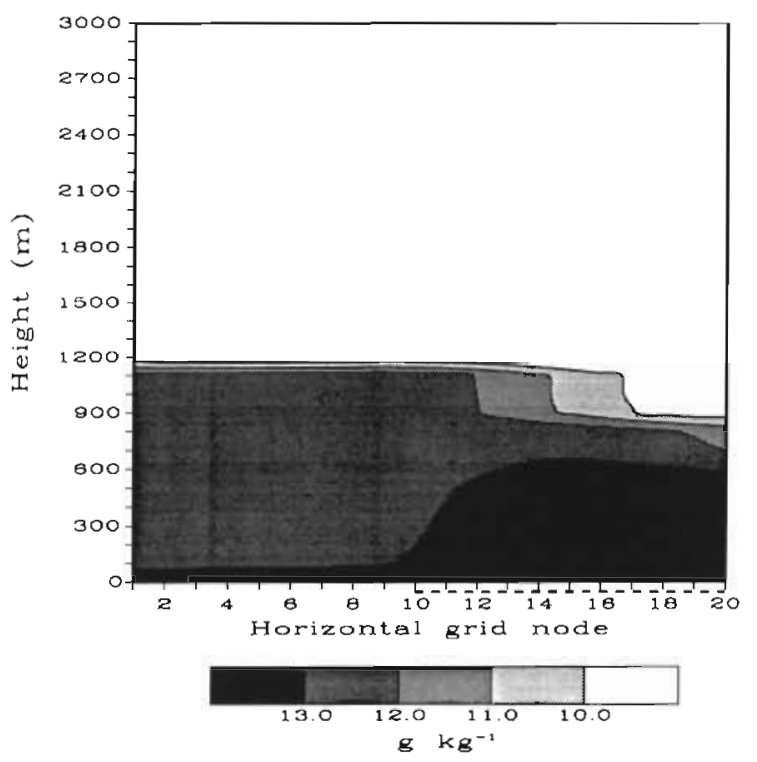

Fig. 14. Vertical cross-section of the specific humidity field in the lower atmosphere at 15:00 h for the 50B 50M surface. The cross-section is taken at the location depicted in Fig. 2. Areas of irrigated maize are indicated by a dashed line along the horizontal axis and unmarked regions are bare soil

the irrigated maize since the prevailing wind moves the drier air away from the vegetation.

Over the course of the day, high transpiration rates within the checkerboard domain and effective mixing by the multiple circulation cells moisten the entire lower layer of the atmosphere over the domain (Fig. 13).
Humidity over the bare soil no longer is as low as it was as earlier in the day. A larger humidity gradient is maintained between bare soil and irrigated maize in the 50B:50M region (Fig. 14). Drier air continues to blow toward the irrigated vegetation and, in turn, the evapotranspiration remains high.

\section{SUMMARY AND CONCLUSIONS}

Influences of characterizing a climate model grid cell as completely covered by an irrigated crop (maize) or by non-irrigated bare soil can be profound. Alternate methods of aggregating subgrid-scale patchiness resulted in large differences in the surface and nearsurface area-averaged temperatures, as well as in the domain-averaged latent (and consequently the sensible and ground) heat fluxes. Classifying a domain with $50 \%$ irrigated maize and $50 \%$ bare soil as completely bare overestimates surface temperatures by up to $4{ }^{\circ} \mathrm{C}$ at midday, and near-surface air temperatures by as much as $1.5^{\circ} \mathrm{C}$. Latent heat flux is underestimated by approximately $180 \mathrm{~W} \mathrm{~m}^{-2}$. The over- and underestimates are reversed when the same domain is classified as irrigated maize. Distinguishing between homogeneous surfaces and regions with a clearly dominant surface type also may be climatically important. Characterizing an area that is $70 \%$ irrigated maize and $30 \%$ bare soil as a homogeneous maize cover, for instance, could produce average surface temperatures that are too low by about $2^{\circ} \mathrm{C}$ and overestimate the area-averaged latent heat flux by up to $90 \mathrm{~W} \mathrm{~m}^{-2}$.

Geographical positioning within the grid cell also affected the domain-averaged temperature and latent heat flux: a nearly linear change was observed when small areas of bare soil occurred downwind of irrigated maize, but when positioned upwind these same areas produced a more nonlinear response. Roughness and soil moisture variations across the domain are the 2 primary variables affecting the surface energy balance Because it is not water-limited, irrigated maize shows an increase in evapotranspiration with the advection of drier air from the bare soil region. The result is a nonlinear decrease in the domain-averaged latent heat flux. The increased roughness of maize as compared to bare soil enhances the fluxes of sensible as well as latent heat, and contributes to the concomitant nonlinear changes in area-averaged surface temperatures. Roughness differences also play a role in the development of small-scale circulation patterns over the domain, accentuating geographical differences in some cases and diminishing them in others. A comparison of 3 domains with different spatial patterns of $50 \%$ irrigated maize and $50 \%$ bare soil showed differences in area-averaged surface temperatures and near-surface 
air temperatures of nearly $1^{\circ} \mathrm{C}$ by late afternoon, and latent heat flux differences over the period of simulation of up to $90 \mathrm{~W} \mathrm{~m}^{-2}$.

Investigations of a greater variety of land surface types and atmospheric conditions are needed to identify the full range of the climatic responses to surface heterogeneity. Our results support the findings that surface heterogeneity, particularly in regions with small but significant areas of a non-dominant surface type, can bias climate model simulations of the surface energy budget. Heterogeneous domains used here appear to scale nearly linearly with the percentage of surface cover. It may be possible, therefore, to represent climate model grid cells with co-dominant surface types by simply averaging their surface responses, as several investigators have proposed. Such an approach seems preferable to the common practice of assigning grid areas to homogeneous surface categories. However, our results also suggest that attention should be paid to the spatial arrangement of land surface elements within a grid cell domain. Model sensitivity results described here indicate the types of biases that may occur if the geographical distribution of surface elements within heterogeneous areas is overlooked. In these cases an alternative surface weighting scheme, perhaps based on seasonal wind patterns, might be an improvement.

Acknowledgements. Portions of this research were supported by the Minnesota Supercomputer lnstitute and a Faculty Summer Research Fellowship, University of Minnesota (K.K.), and NASA grants NAG 5-853 and NAGW-1884 (C.J.W.). Professor Roger Pielke graciously provided the atmospheric model used in this work.

\section{LITERATURE CITED}

Abramopoulos, F., Rosenzweig, C., Choudhury, B. (1988). Improved ground hydrology calculations for global climate models (GCMs): soil water movement and evapotranspiration. J. Climate 1: 921-941

André, J.-C., Bougeault, P., Goutorbe, J.-P. (1990). Regional estimates of heat and evaporation fluxes over non-homogeneous terrain. Examples from the HAPEX-MOBILHY programme. Bound.-Layer Meteor. 50: 77-108

Avissar, R. (1991). A statistical-dynamical approach to parameterize subgrid-scale land-surface heterogeneity in climate models. Surv. Geophys. 12: 155-178

Avissar, R., Mahrer, Y. (1988). Mapping frost-sensitive areas with a three-dimensional local-scale numerical model. Part I: Physical and numerical aspects. J. appl. Meteor. 27: 400-413

Avissar, R., Pielke, R. A. \{1989\}. A parameterization of heterogeneous land surfaces for atmospheric numerical models and its impact on regional meteorology. Mon. Weather Rev. 117: 2113-2136

Avissar, R., Pielke, R. A. (1991). The impact of plant stomatal control on mesoscale atmospheric circulations. Agric. For Meteorol. 54: 353-372

Bonan, G. B., Pollard, D., Thompson, S. L. (1993). Influence of subgrid-scale heterogeneity in leaf area index, stomatal resistance, and soil moisture on grid-scale land-atmosphere interactions. J. Climate 6: 1882-1897

Chang, J.-H. (1958). Ground temperature, Vol. 2. Harvard University Blue Hill Meteorological Observatory, Milton, $\mathrm{MA}$

Clapp, R. B., Hornberger, G. M. (1978). Empirical equations for some soil hydraulic propertıes. Water Resour Res. 14 $601-604$

Crowe, P. R. (1971). Concepts in climatology. St. Martin's Press, New York

Dickinson, R. E. (1984). Modeling evapotranspiration for three-dimensional global climate models. In: Hansen, J. E., Takahashi, T (eds.) Climate processes and climate sensitivity. Geophysical Monograph 29, American Geophysical Union, Washington, DC, p. 58-72

Dickinson, R. E., Hanson, B. (1984). Vegetation-albedo feedbacks. ln: Hansen, J. E., Takahashi, T (eds.) Climate processes and climate sensitivity. Geophysical Monograph 29, American Geophysical Union, Washington, DC, p. $180-186$

Dickinson, R. E. Henderson-Sellers, A. (1988). Modeling tropical deforestation: a study of GCM land-surface parameterizations. Q. J. R. Meteorol. Soc. 114:439-462

Doran, J. C., Barnes, F. J., Coulter, R. L., Crawford, T L., Baldocchi, D. D., Balick, L., Cook, D. R., Cooper, D., Dobosy, R. J., Dugas, W. A., Fritschen, L., Hart, R. L., Hipps, L., Hubbe, J. M., Gao, W., Hicks, R., Kirkham, R. R., Kunkel, K. E., Martin, T. J., Meyers, T P., Porch, W., Shannon, J. D., Shaw, W. J., Swiatek, W., Whiteman, C. D. (1992). The Boardman regional flux experiment. Bull. Am. Meteorol. Soc. 73: 1785-1795

Ducoudré, N. I., Laval, K., Perrier, A. (1993). SECHIBA, a new set of parameterizations of the hydrologic exchanges at the land-atmosphere interface within the LMD atmospheric general circulation model. J. Climate 6: 248-273

Henderson-Sellers, A., Pitman, A. J. (1992). Land-surface schemes for future climate models: specification, aggregation, and heterogeneity. J. geophys. Res. 97: 2687-2696

Hillel, D. (1982). Introduction to soil physics. Academic Press, New York

Idso, S. B., Jackson, R. D., Reginato, R. J., Kimball, B. A., Nakayama, F. S. (1975). The dependence of bare soil albedo on soil water content. J. appl. Meteorol. 14 $109-113$

Jarvis, P. G. (1976). The interpretation of the variations in leaf water potential and stomatal conductance found in canopies in the field. Phil. Trans. R. Soc. B 273: 593-610

Klink, K. (1992). Evaluating climate-vegetation interactions at climate model sub-grid scales. Publ. Climatol. 45(1)

Körner, C., Schell, J. A., Bauer, H. (1979). Maximum leaf diffusive conductance in vascular plants. Photosynthetica 13: $45-82$

Koster, R. D., Suarez, M. J. (1992). Modeling the land surface boundary in climate models as a composite of independent vegetation stands. J. geophys. Res. 97: 2697-2715

Lhomme, J.-P. (1992). Energy balance of heterogeneous terrain: averaging the controlling parameters. Agric. For Meteorol. 61.11-21

Mahfouf, J.-F., Richard, E., Mascart, P. (1987). The influence of soil and vegetation on the development of mesoscale circulations. J. Clim. appl. Meteorol. 26: 1483-1495

Mahrer, Y., Pielke, R. A. (1977). A numerical study of the air flow over irregular terrain. Contrib. Atmos. Phys. 50: 98-113

Mahrer, Y., Pielke, R. A. (1978). A test of an upstream spline interpolation technique for the advective terms in a 
numerical mesoscale model. Mon. Weather Rev. 106: $818-830$

Mascart, P., Taconet, O., Pinty, J.-P., Mehrez, M. B. (1991). Canopy resistance formulation and its effect in mesoscale models: a HAPEX perspective. Agric. For. Meteorol. 54: $319-351$

Matthews, E. (1983). Global vegetation and land use: new high-resolution data bases for climate studies. J. Clim. appl. Meteorol. 22: 474-487

McCumber, M. C., Pielke, R. A. (1981). Simulation of the effects of surface fluxes of heat and moisture in a mesoscale numerical model. 1. Soil layer. J. geophys. Res. 86: $9929-9938$

McNider, R. T., Pielke, R. A. (1981). Diurnal boundary-layer development over sloping terrain. J. Atmos. Sci. 38: $2198-2212$

Mintz, Y. (1984). The sensitivity of numerically simulated climates to land surface boundary conditions. In: Houghton, J. T. (ed.) The global climate. Cambridge University Press, Cambridge, p. 79-105

Monteith, J. L. (1973). Principles of environmental physics. Edward Arnold, London

Nobel, P. S. (1983). Biophysical plant physiology and ecology. W. H. Freeman and Co., San Francisco

Oke, T R. (1978). Boundary layer climates. Methuen \& Co., London

Peixoto, J. P., Oort, A. H. (1992). Physics of climate. American Institute of Physics, New York

Pielke, R. A. (1974). A three-dimensional numerical model of the sea breezes over South Florida. Mon. Weather Rev. 102: $115-139$

Pielke, R. A. (1984). Mesoscale meteorological modeling. Academic Press, Orlando

Segal, M., Arritt, R. W. (1992). Nonclassical mesoscale circulations caused by surface sensible heat-flux gradients. Bull. Am. Meteorol. Soc. 73: 1593-1604

Segal, M., Avissar, R., McCumber, M.C., Pielke, R.A. (1988). Evaluation of vegetation effects on the generation and modification of mesoscale circulations. J Atmos. Sci. 45 $2268-2292$

Segal, M., Schreiber, W. E., Kallos, G., Garratt, J. R., Rodi, A., Weaver, J., Pielke, R. A. (1989). The impact of crop areas in northeast Colorado on midsummer mesoscale thermal circulations. Mon. Weather Rev. 117: 809-825

Sellers, P. J., Mintz, Y., Sud, Y C., Dalcher, A. (1986). A Sim-

Editor: V. Meentemeyer, Athens, Georgia, USA ple Biosphere model ( $\mathrm{SiB}$ ) for use within general circulation models. J. Atmos. Sci. 43: 505-531

Shukla, J., Mintz, Y (1982). Influence of land-surface evapotranspiration on the earth's climate. Science 215: $1498-1501$

Shuttleworth, W. J., Wallace, J. S. (1985). Evaporation from sparse crops - an energy combination theory. Q. J. R. Meteorol. Soc. 111:839-885

Steyn, D. G., McKendry, I. G. (1988). Quantitative and qualitative evaluation of a three-dimensional mesoscale numerical model simulation of a sea breeze in complex terrain. Mon. Weather Rev. 116: 1914-1926

Sud, Y C., Shukla, J., Mintz, Y. (1988). Influence of land surface roughness on atmospheric circulation and precipitation: a sensitivity study with a general circulation model. J. appl. Meteorol. 27: 1036-1054

Taylor, H. M., Klepper, B. (1973). Rooting density and water extraction patterns for corn (Zea mays L.). Agron. J. 65: 965-968

Verseghy, D.L., McFarlane, N.A., Lazare, M. (1993). CLASS - a Canadian land surface scheme for GCMs. II. Vegetation model and coupled runs. Int. J. Climatol. 13: 347-370

Wetzel, P. J., Chang, J.-T (1988). Evapotranspiration from ronuniform surfaces: a first approach for short-term numerical weather prediction. Mon. Weather Rev. 116: $600-621$

Willmott, C. J., Ackleson, S. G., Davis, R. E., Feddema, J. J., Klink, K., Legates, D. R., O'Donnell, J., Rowe, C. M. (1985a). Statistics for the evaluation and comparison of models. J. geophys. Res. 90: 8995-9005

Willmott, C. J., Klink, K. (1986). A representation of the terrestrial biosphere for use in global climate studies. In: Proceedings of the ISLSCP Conference, Rome, Italy, December 1985. ESA SP-248, 1986. European Space Agency, Paris, p. 109-112

Willmott, C. J., Rowe, C. M., Mintz, Y. (1985b). Climatology of the terrestrial seasonal water cycle. J. Climatol. 5: $589-606$

Wilson, M. F., Henderson-Sellers, A. (1985). A global archive of land cover and soils data for use in general circulation climate models. J. Climatol. 5: 119-143

Wilson, M. F., Henderson-Sellers, A., Dickinson, R. E. Kennedy, P. J. (1987). Sensitivity of the Biosphere-Atmosphere Transfer Scheme (BATS) to the inclusion of variable soil characteristics. J. Clim. appl. Meteorol. 26: 341-362

Manuscript first received: March 5, 1994

Revised version accepted: May 31, 1994 